\title{
Extracorporeal Phototherapy
}

\author{
Andreas Buser $^{\mathrm{a}} \quad$ Nina Worel ${ }^{\mathrm{b}}$ \\ ${ }^{a}$ Regional Blood Transfusion Service, Swiss Red Cross Basel and Department of Hematology, University Hospital \\ Basel, Basel, Switzerland; ${ }^{b}$ Department of Blood Group Serology and Transfusion Medicine, University Hospital \\ Vienna, Vienna, Austria
}

Ever since its first introduction by Richard Edelson in the early 1980s of the 20th century, extracorporeal photopheresis (ECP) has been more and more used nowadays in different clinical conditions. Today, not only inline systems as in the very beginning but also offline technologies are used with an excellent safety profile. Its application as a treatment option is not limited to the early indications such as cutaneous T-cell lymphoma but has extended to various diseases caused by an involvement of the immune system mainly in dermatology, solid organ and hematopoietic stem cell transplantation. The American Society of Apheresis has listed ECP for several indications in their latest guidelines, and also the German Society for Transfusion Medicine and Immunohematology published a recommendation on the use of ECP.

In this issue of Transfusion Medicine and Hemothera$p y$ with a special focus on ECP, we are happy to be able to have manuscripts from experts in the field (original research articles and review articles) which give an excellent overview over the technology and its use in different diseases. In an original research article, Helmberg et al. [1] report on the differences in cell composition and induction of apoptosis between offline und inline procedures, discussing a yet unsolved debate between users of either approach.

Drexler et al. [2] report on the use of ECP in graftversus-host disease (GvHD). Today, ECP is a well-established treatment option in chronic GvHD, but data for its use in acute GvHD are not yet so robust. This review gives a very comprehensive overview of ECP used in patients after allogeneic hematopoietic stem cell transplantation experiencing steroid refractory GvHD.

Benazzo et al. [3] describe in their original research article the outcome of lung transplant recipients given ECP as an add-on therapy for antibody-mediated rejection. In this large single-center retrospective analysis covering consecutive lung transplant recipients from 2010 to the end of 2019, ECP reduces de novo donor-specific antibodies and is able to restore pulmonary function in up to $50 \%$ of patients.

In a very comprehensive review, Vieyra-Garcia and Wolf [4] give an excellent overview on ECP as immunotherapy. Even though they state that the exact mechanisms of how ECP works are not yet fully understood, they give an excellent overview of the changes induced in the immune system when using ECP.

Taken all together, the editors are convinced that with the fine work by the authors the reader will find this issue of Transfusion Medicine and Hemotherapy of benefit both scientifically and practically in supporting their patients.

$\begin{array}{ll}\text { References } & \text { Helmberg W, Sipurzynski S, Groselje-Strehle } \\ & \text { A, Greinix H, Schlenke P. Does offline beat } \\ & \text { inline treatment: investigation into extracor- } \\ & \text { poreal photopheresis. Transfus Med He- } \\ & \text { mother. 2020;47(3):1-7. } \\ 2 & \text { Drexler B, Buser A, Infanti L, Stehle G, Halter } \\ & \text { J, Holbro A. Extracorporeal photopheresis in } \\ & \text { graft-versus-host disease. Transfus Med He- } \\ & \text { mother.2020;47(3). DOI: 10.1159/000508169. } \\ 3 & \text { Benazzo A, Worel N, Schwarz S, Just U, } \\ & \text { Nechay A, Lambers C, et al. Outcome of ex- } \\ & \text { tracorporeal photopheresis as an add-on ther- } \\ & \text { apy for antibody-mediated rejection in lung } \\ & \text { transplant recipients. Transfus Med Hemoth- } \\ & \text { er. 2020;47(3). DOI: 10.1159/000508170. } \\ & \begin{array}{l}\text { Vieyra-Garcia PA, Wolf P. Extracorporeal } \\ \text { photopheresis. A case of immunotherapy }\end{array} \\ & \text { ahead of its time. Transfus Med Hemother. } \\ & 2020 ; 47(3) \text {. DOI: } 10.1159 / 000508479 .\end{array}$

(25)

